\title{
Extractive Determination of Co (II) and Ni (II) by N, N'-bis(5-(4-nitrophenyl)diazenyl)-2- hydroxybenzylideneamino) ethylenediimine (NDHBDED) Impregnated with Alumina by pH Dependent SPS
}

\author{
MD. FARIDUR RAHMAN ${ }^{1 *}$, BISWAJIT CHAKRABORTY² and TANMOY DAS ${ }^{1}$ \\ 'Department of Chemistry, University of Burdwan, Burdwan-713104, India. \\ Vivekananda Mahavidyalaya, Burdwan, WB, India. \\ *Corresponding Authors E-mail: faridur1979@gmail.com \\ http://dx.doi.org/10.13005/ojc/320328
}

(Received: May 08, 2016; Accepted: June 28, 2016)

\begin{abstract}
A new azo dye Schiff base analytical reagent, namely N, N' -bis(5-(4-nitrophenyl)diazenyl)2-hydroxybenzylideneamino)ethylenediimine (NDHBDED) has been synthesized and it was impregnated with alumina for extractive determination of metal ions. In this report the solid sorbent matrix was used for the extraction of $\mathrm{Co}$ (II) and Ni (II) ions by $\mathrm{pH}$ dependent SPS method. The maximum molar absorbances were at $445 \mathrm{~nm}$ and $508 \mathrm{~nm}$ at pH 4.5 and 5.0 for Co (II) and $\mathrm{Ni}$ (II) ions respectively. The Beer's law range was $5-100 \mu \mathrm{g} / \mathrm{ml}$ for both the metal ions. Job's method and mole-ratio method showed that metal-ligand ratio in the complexes to be 1:1. The Molar absorptivity for Co (II) and Ni (II) were $1.351 \times 10^{-4} \mathrm{~L} \mathrm{~mol}^{-1} \mathrm{~cm}^{-1}$ and $1.925 \times 10^{-4} \mathrm{~L} \mathrm{~mol}^{-1} \mathrm{~cm}^{-1}$ respectively. The Sandell's sensitivity was $0.005 \mu \mathrm{g} / \mathrm{cm}^{2}$ and $0.004 \mu \mathrm{g} / \mathrm{cm}^{2}$ for Co (II) and Ni (II) ions respectively. The proposed method was successfully applied to the determination of each metal ion in real samples and tap water.
\end{abstract}

Keywords: Azo dye Schiff base analytical reagent, Co (II) and Ni (II) complexes, pH metric SPS.

\section{INTRODUCTION}

The determination of metal ions in natural samples is very important part of environment and human health ${ }^{1-4}$. Metal ions-ligands coordination complexes are the intense analytical approach for the determination of metal ions of the environmental samples ${ }^{5-8}$. Some metal ions are constituents of the metabolic enzyme in biological system, but their toxicity influence for direct determination in environmental samples. Cobalt and nickel are most common transitions metals. The significance of cobalt as transitions metal lies in its wide spectrum of applications such as in industries and consumers 
products. Another transition metal nickel is vital and its compounds are toxic for many biological systems. It can be considered is one of the frontier elements in the alloys industries for stainless steels, cast iron, german silver and monel metal and also found in many heat resistant alloys. It also plays vital roles in the biology of micro-organisms, plants and is an essential element in human $\operatorname{diet}^{9-13}$.

Literature survey reveals several instrumental techniques have been employed for the determination of $\mathrm{Co}$ (II) and Ni (II), such as spectrofluorimetry, X-ray fluorescence spectrometry, neutron activation analysis, atomic absorption spectrometry, inductively coupled plasma mass spectrometry, chemiluminescence, of which UV-visible solid phase spectrophotometry is preferred because of its low cost, rapidity and easy handling ${ }^{14-17}$. Several methods such as liquidliquid extraction, micellar mediated extraction, coprecipitation, cloud point extraction, electrochemical extraction and solid phase extraction are adopted for metal ions extraction ${ }^{18-22}$. But disadvantages such as significant chemical additives, solvent losses, complex equipments, considerable secondary waste and time consuming problems limit the application of most of these techniques. Solid phase spectrophotometric (SPS), however, solves these problems as it offers several advantages. This technique is also attractive as this is no need to use organic solvents, which may cause toxic effects.

A wide variety of reagent has been reported for the spectrophotometric reagents for determination of Co (II) and Ni (II). Some reagents were identified, but they suffer low sensitivity, interference from diverse ions. The azo dye Schiff base compounds have been extensively studied because of their biological and structural importance. Several azo dye Schiff base ligands containing $\mathrm{N}_{2} \mathrm{O}_{2}$-donor site have been proposed as spectrophotometric reagents for metal ions ${ }^{23-25}$. The importance of these compounds lies mainly in their specific and selective reactions with metal ions which forms stable complexes. In the present report, we introduced a new azo dye Schiff base ligand N, N'-bis(5-(4nitrophenyl)diazenyl)-2-hydroxybenzylideneamino) ethylenediimine (NDHBDED) for selective solid phase spectrophotometric (SPS) determination of some heavy metal ions from environmental samples. We impregnated the azo dye Schiff base ligand with alumina for the complexation with Co (II) and Ni (II) ions prior to solid phase spectrophotometric (SPS) determination of these metal ions.

\section{MATERIALS AND METHODS}

\section{Instrumentation}

The absorbance measurements were recorded using Shimadzu UV-Vis spectrophotometer (UV-1800) fitted with $1 \mathrm{~cm}$ quartz cells. A mechanical shaker (BOD-incubator, YONA Mfg. Indian Instruments Manufacture Co., Kol-12) was used throughout the experiments. The $\mathrm{pH}$ measurements were carried out by a labtronic $\mathrm{pH}$ meter (Model-23) equipped with a combined glass-calomel electrode.

\section{Reagents and Solutions}

Extra pure reagents were of analytical grade from E. Marck, Germany and other metal<smiles>NN(C(=O)[O-])c1ccc(N=NCl)cc1</smiles>

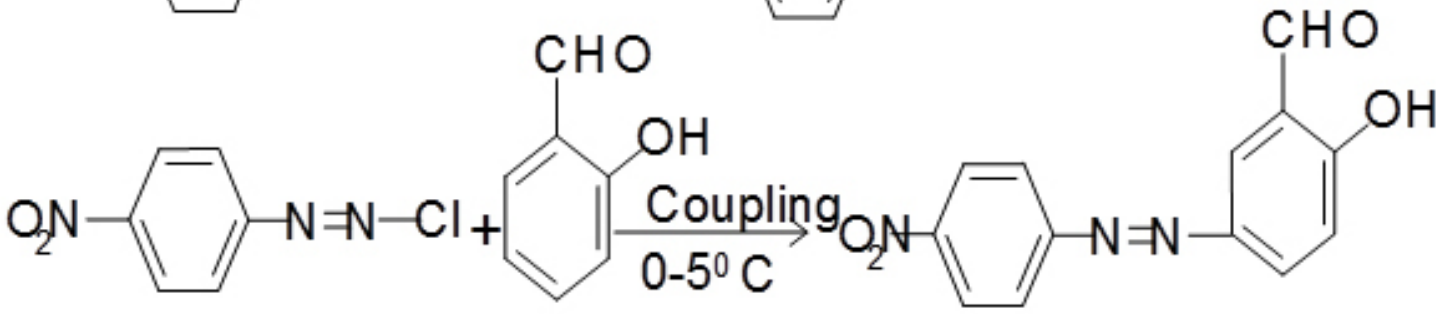

Fig. 1: The reaction scheme of the Azo Coupling of salicyldehyde 
salts from $\mathrm{BDH}$, India also were of analytical grade. p-nitroaniline, salicyldehyde and ethylendiamine from Sigma and Aldrich were used for the complexing agent. A neutral solid alumina was of analytical grade reagent for the determination of Co (II) and Ni (II) from Oxford Lab., Mumbai, India. Standard stock solutions of Co (II) and Ni (II) were prepared by dissolving appropriate amount of pure grade chemicals in double distilled deionised water with addition of few drops of conc. $\mathrm{HCl}$. The working solutions were prepared by diluting the stock solution with bi-distilled water. The solutions of the complexing agent were prepared in ethanol-methanol mixture.

\section{Synthesis of the chelating ligand}

The azo dye Schiff base ligand N, N' -bis(5-(4nitrophenyl)diazenyl)-2-hydroxybenzylideneamino) ethylenediimine (NDHBDED) ligand was synthesized by our previous reported method which was a two steps method : (a) Azo coupling of salicyldehyde<smiles>O=[N+]([O-])c1ccc(N=Nc2ccc(O)c(C=NCCN=Cc3cc(N=Nc4ccc([N+](=O)[O-])cc4)ccc3O)c2)cc1</smiles>

N, N' -bis(5-(4-nitrophenyl)diazenyl)-2-hydroxybenzylideneamino)ethylenediimine(NDHBDED)

Fig. 2: The reaction scheme of synthesis of the Azo Dye Schiff Base Ligand

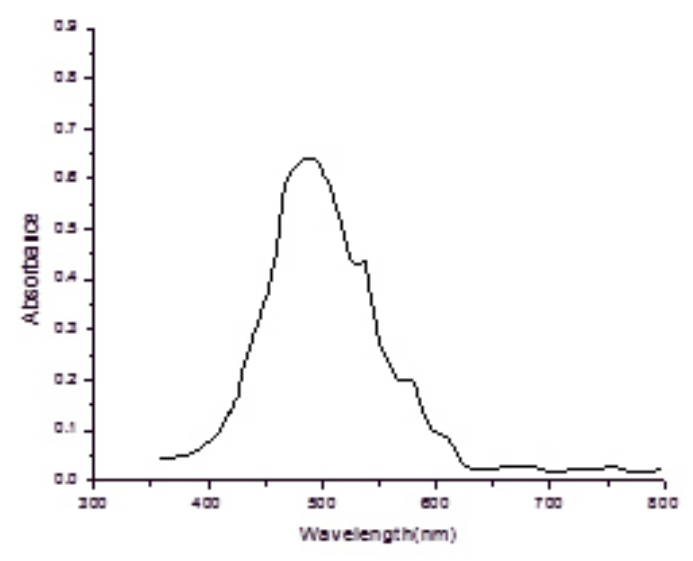

Fig. 3: Absorbance spectra of the chelating ligand

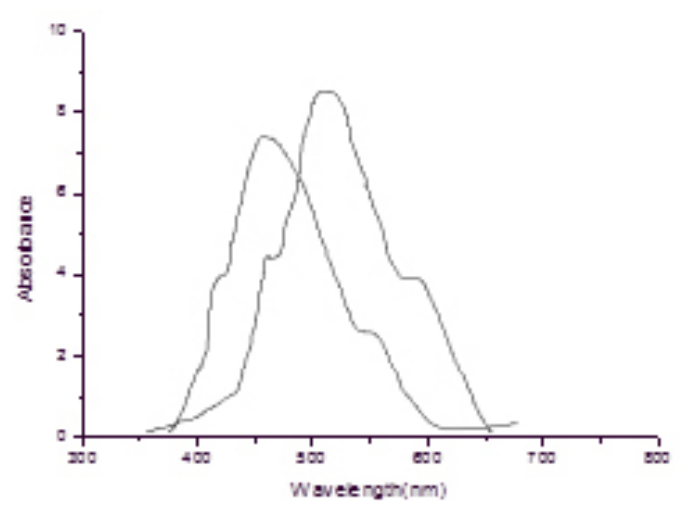

Fig. 4: Absorbance spectra for the Co (II) -NDHBDED and Ni (II) - NDHBDED complexes 
(b) Synthesis of the Azo Dye Schiff Base ligand (NDHBDED). The scheme of synthesis of the ligand is illustrated in Fig. 1 \& 2 .

\section{Analytical Procedures}

$2 \mathrm{~g}$ of the azo dye Schiff base (NDHBDED) chelating reagent was impregnated on the surface of $4.0 \mathrm{~g}$ of alumina at the ratio $1: 2$ in ethanolmethanol mixture and stirred for 30 minutes at room temperature. The resulting composition was left in an oven at $60^{\circ} \mathrm{C}$ for 48 hours. After drying, the sorbent was ground into powder for metal ions extraction. A series of standard or sample solution of $25 \mathrm{ml}$ of 0.1 (M) Co (II) and 0.1 (M) Ni (II) in each flask of $100 \mathrm{ml}$ and $\mathrm{pH}$ was adjusted from 4.0 to 5.0 using

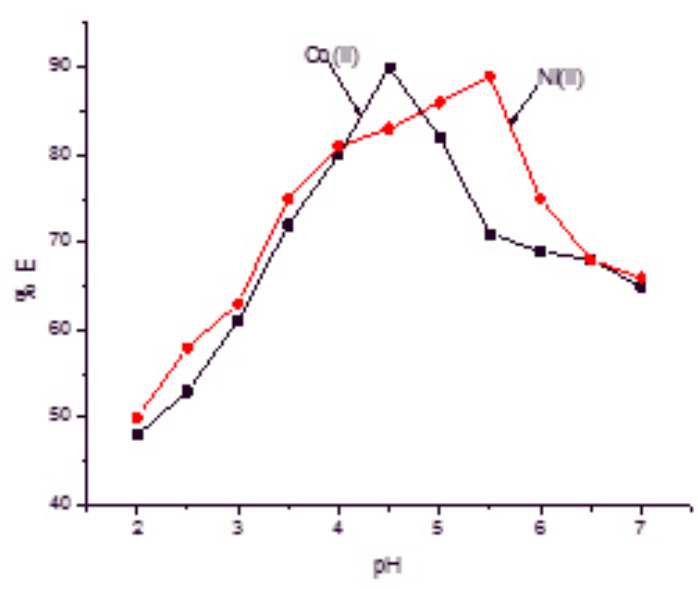

Fig. 5: Effect of pH on the extraction of both of $\mathrm{Co}$ (II) and Ni (II) ions

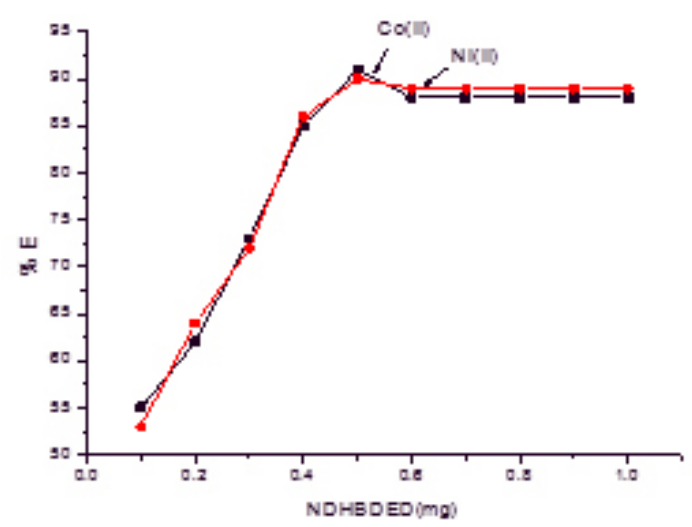

Fig. 7: Effect of the reagent concentration on the extraction of $5 \mu \mathrm{g} / \mathrm{ml}$ of Co (II) \& Ni (II) ions
$\mathrm{HCl}(0.1 \mathrm{M})$ and $\mathrm{NaOH}(0.1 \mathrm{M})$ solutions. $200 \mathrm{mg}$ of sorbents were added to the above solutions and were shaken vigorously by a mechanical shaker at room temperature for 30 minutes to facilitate adsorption of the metal ions onto the adsorbents.

\section{RESULTS AND DISCUSSION}

UV-Vis spectra for NDHBDED is recorded by our previous report which was at $\lambda_{\max } 500 \mathrm{~nm}$ and the spectra of the complexes of Co (II) - NDHBDED and Ni (II) - NDHBDED give maximum absorbance at $\lambda_{\text {max }} 445 \mathrm{~nm}$ and $\lambda_{\text {max }}$ $508 \mathrm{~nm}$ respectively (Fig. $3 \& 4$ ). N, N' -bis (5-(4nitrophenyl)diazenyl)-2-hydroxybenzylideneamino)

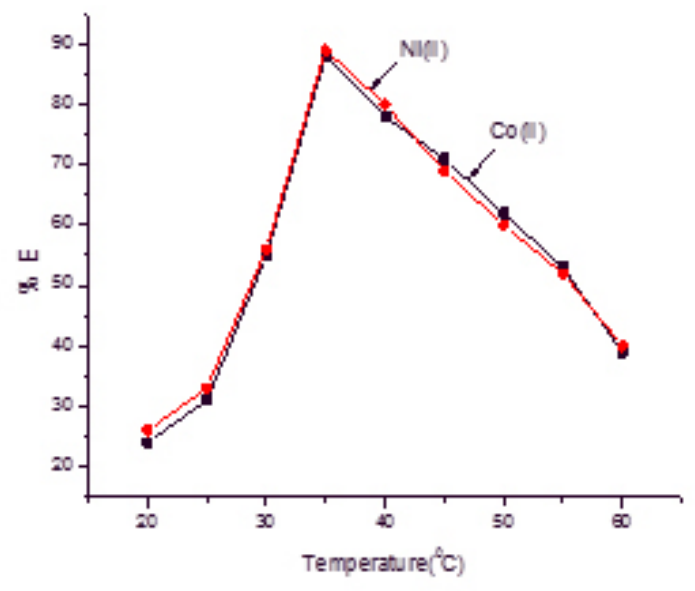

Fig. 6: Effect of temperature on the extraction both $\mathrm{Co}$ (II) and $\mathrm{Ni}$ (II) ions

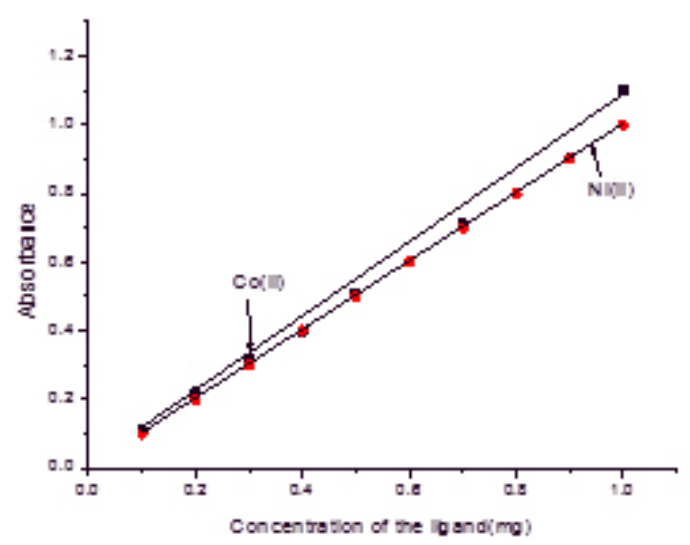

Fig. 8: Mole-Ratio of NDHBDED concentration to $\mathrm{Co}$ (II) and $\mathrm{Ni}$ (II) ions 
ethylenediimine(NDHBDED) forms coloured complexes with $\mathrm{Co}$ (II) and Ni (II) ions which are stable and their extraction could be quantitative at $\mathrm{pH} 4.5$ and 5.0 respectively. The calibration curve were constructed by plotting absorbance against the amount of $\mathrm{Co}$ (II) and $\mathrm{Ni}$ (II) ions in the concentration range of $5-100 \mu \mathrm{g} / \mathrm{ml}$ of each. The analytical characteristics of the complexes are given in [Table 1].

\section{Influences of $\mathrm{pH}$}

The $\mathrm{pH}$ of the aqueous samples is the very important factor for the quantitative recoveries of the metal ions in the solid phase spectrophotometric (SPS) studies, the influences of $\mathrm{pH}$ of the analyte solutions on the recoveries of $\mathrm{Co}$ (II) and $\mathrm{Ni}$ (II) on the solid adsorbents in the $\mathrm{pH}$ range $2-7.5$. The quantitative extraction ( $>87 \%$ ) found at the $\mathrm{pH} 4.5$ and 5.0 respectively for Co (II) and Ni (II). Hence, $\mathrm{pH}$ 4.5- 5.0 was considered for the further studies. The results are shown in [Fig.5].

\section{Influence of temperature}

The effect of temperature on the percentage of extraction of $5 \mathrm{ig} / \mathrm{ml}$ of each $\mathrm{Co}$ (II) and $\mathrm{Ni}$ (II) was studied in the range of $20-60^{\circ} \mathrm{C}$ at $\mathrm{pH}$ range 4.5 to 5.0. The results showed in Fig.6, that the maximum percentage of sorption of both the metal ions is found at $35^{\circ} \mathrm{C}$, Hence, $35^{\circ} \mathrm{C}$ was considered for the further studies.

\section{Effect of reagent (NDHBDED) concentration}

The effect of the reagent concentration impregnated with alumina was investigated in the range of 0.1 to $1.0 \mathrm{mg}$. The results showed that the extraction of metal ions was increased on the addition of the reagent. It was found that the quantitative extraction (> $90 \%$ ) at $0.5 \mathrm{mg}$. But beyond this range of reagent concentration does not influence on the extraction of the metal ions. The results are given in Fig.7.

\section{Effect of Co (II) and Ni (II) ion concentration}

The percentage extraction efficiency of the metal ions in the range of $5-100 \mu \mathrm{g} / \mathrm{ml}$ was studied at a fixed amount of the reagent $(0.5 \mathrm{mg})$ on the solid matrix at $\mathrm{pH}$ 5.0. Almost $87 \%$ of both the metal ions were extracted by the sorbent [Table 2]

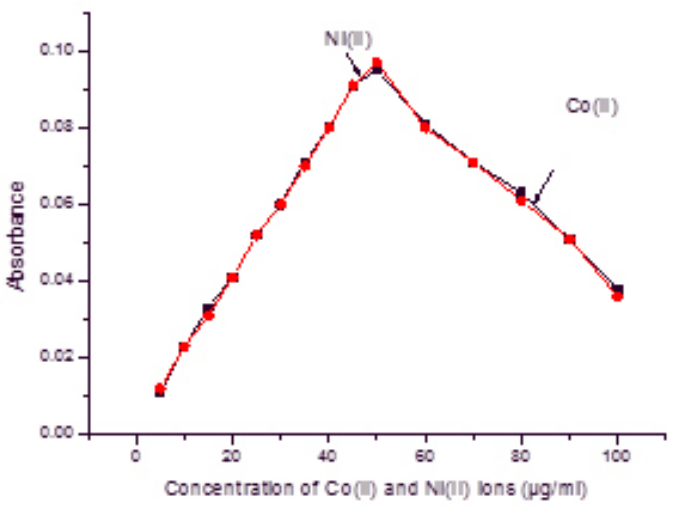

Fig. 9: Job's continuous variation method

Table 1: Physical and Analytical Characteristics of Co (II) \& Ni (II) - NDHBDED Complexes

\begin{tabular}{|c|c|c|}
\hline \multirow{2}{*}{ Parameters } & \multicolumn{2}{|c|}{ Value } \\
\hline & Co (II) & $\mathrm{Ni}(\mathrm{II})$ \\
\hline Molar absorbance $\left(\lambda_{\max }\right)$ & $445 \mathrm{~nm}$ & $508 \mathrm{~nm}$ \\
\hline Limit of Detection $(\mu \mathrm{g} / \mathrm{ml})$ & $0.1-1.0$ & $0.1-1.0$ \\
\hline Beer's law range & $5-100 \mu \mathrm{g} / \mathrm{ml}$ & $5-100 \mu \mathrm{g} / \mathrm{ml}$ \\
\hline Molar absorptivity & $1.351 \times 10^{-4} \mathrm{~L} \mathrm{~mol}^{-1} \mathrm{~cm}^{-1}$ & $1.925 \times 10^{-4} \mathrm{~L} \mathrm{~mol}^{-1} \mathrm{~cm}^{-1}$ \\
\hline Stability Constant $(\beta)$ & $3.39 \times 10^{7}$ & $3.92 \times 10^{7}$ \\
\hline $\mathrm{pH}$ & 4.5 & 5.0 \\
\hline Temperature & $35^{\circ} \mathrm{C}$ & $35^{\circ} \mathrm{C}$ \\
\hline Standard deviation & 0.156 & 0.215 \\
\hline Composition (Metal:Ligand) & $1: 1$ & $1: 1$ \\
\hline Sandell's Senstvity & $0.005 \mu \mathrm{g} / \mathrm{cm}^{2}$ & $0.004 \mu \mathrm{g} / \mathrm{cm}^{2}$ \\
\hline Magnetic Moment $\left(\mu_{\text {eff }}\right)$ & $3.82 \mathrm{BM}$ & $2.82 \mathrm{BM}$ \\
\hline
\end{tabular}


The Stoichiometry of the Co (II) and Ni (II) - Mole-Ratio method

\section{NDHBDED}

The stoichiometry of Co (II) and Ni (II) NDHBDED complex was determined by Mole-Ratio method and Job's method of continuous variation at fixed absorbance $\lambda_{\text {max }} 500 \mathrm{~nm}$.
The extractions of the metal ions were carried out in the range of 0.1 to $1.0 \mathrm{mg}$ of the reagent concentration. The natures of the curves were straight line for both the metal ions which predicting

Table 2: Effect of Co (II) and Ni (II) ions concentration on the percntage extraction of the solid sorbent matrix at $\mathrm{pH} 5.0$ at room temperature

\begin{tabular}{|c|c|c|c|c|c|c|c|}
\hline \multirow[b]{2}{*}{$\begin{array}{l}\text { Used } \\
(\mu \mathrm{g} / \mathrm{ml})\end{array}$} & \multicolumn{3}{|c|}{ Co (II) } & \multirow[b]{2}{*}{$\begin{array}{c}\text { Used } \\
(\mu \mathrm{g} / \mathrm{ml})\end{array}$} & \multirow[b]{2}{*}{$\begin{array}{c}\text { Extracted } \\
(\mu \mathrm{g} / \mathrm{ml})\end{array}$} & \multicolumn{2}{|c|}{ Ni (II) } \\
\hline & $\begin{array}{c}\text { Extracted } \\
(\mu \mathrm{g} / \mathrm{ml})\end{array}$ & $\% \mathrm{E}$ & $\%$ RSD & & & $\% E$ & $\%$ RSD \\
\hline 5 & 2.5 & 50 & 0.13 & 5 & 2.4 & 48 & 0.11 \\
\hline 10 & 6.2 & 62 & 0.11 & 10 & 6.1 & 61 & 0.21 \\
\hline 15 & 10.8 & 72 & 0.13 & 15 & 10.9 & 72.66 & 0.12 \\
\hline 20 & 14.8 & 74 & 0.11 & 20 & 14.7 & 73.5 & 0.08 \\
\hline 25 & 20.7 & 82.8 & 0.12 & 25 & 20.6 & 82.4 & 0.15 \\
\hline 30 & 25.12 & 83.73 & 0.13 & 30 & 24.92 & 83.06 & 0.13 \\
\hline 35 & 30.88 & 88.22 & 0.09 & 35 & 31.83 & 90.94 & 0.14 \\
\hline 40 & 35.80 & 89.2 & 0.08 & 40 & 34.88 & 87.2 & 0.12 \\
\hline 45 & 40.60 & 90.22 & 0.11 & 45 & 41.50 & 92.22 & 0.07 \\
\hline 50 & 46.12 & 92.24 & 0.14 & 50 & 44.92 & 89.84 & 0.15 \\
\hline 60 & 54.1 & 90.16 & 0.09 & 60 & 55.0 & 91.66 & 0.16 \\
\hline 70 & 64.3 & 91.85 & 0.08 & 70 & 63.1 & 90.14 & 0.09 \\
\hline 80 & 73.5 & 91.87 & 0.11 & 80 & 72.5 & 90.62 & 0.12 \\
\hline 90 & 82.3 & 91.44 & 0.1 & 90 & 81.1 & 90.11 & 0.16 \\
\hline 100 & 88.6 & 88.6 & 0.12 & 100 & 89.6 & 89.6 & 0.11 \\
\hline
\end{tabular}

Table 3: Separation of $1 \mu \mathrm{g} / \mathrm{ml}$ each of Co (II) and Ni (II) from binary mixtures in a sample volume of $50 \mathrm{ml}$

\begin{tabular}{|c|c|c|c|c|c|c|c|}
\hline \multirow[t]{2}{*}{ Ions } & \multirow{2}{*}{$\begin{array}{c}\text { Amount } \\
(\mathrm{mg})\end{array}$} & \multicolumn{2}{|c|}{ \% Recovery } & \multirow[t]{2}{*}{ Ions } & \multirow{2}{*}{$\begin{array}{c}\text { Amount } \\
(\mathrm{mg})\end{array}$} & \multicolumn{2}{|c|}{ \% Recovery } \\
\hline & & Co (II) & $\mathrm{Ni}$ (II) & & & Co (II) & $\mathrm{Ni}$ (II) \\
\hline $\mathrm{Na}^{+}$ & 5 & 88.5 & 89.5 & $\mathrm{Cl}^{-}$ & 5 & 88.9 & 89.2 \\
\hline $\mathrm{K}^{+}$ & 5 & 88.7 & 88.8 & $\mathrm{Br}$ & 5 & 89.6 & 88.6 \\
\hline $\mathrm{Cd}^{2+}$ & 5 & 86.9 & 89.7 & $\mathrm{SO}_{4}{ }^{2-}$ & 5 & 90.2 & $89 . .5$ \\
\hline $\mathrm{Ca}^{2+}$ & 5 & 87.8 & 89.1 & $\mathrm{ClO}_{3}^{-}$ & 5 & 91.1 & 88.6 \\
\hline $\mathrm{Mg}^{2+}$ & 5 & 88.6 & 89.5 & $\mathrm{NO}_{3}^{-}$ & 5 & 89.2 & 88.2 \\
\hline $\mathrm{Ba}^{3+}$ & 2.5 & 91.1 & 88.6 & $\mathrm{CO}_{3}^{2-}$ & 2.5 & 88.7 & 89.3 \\
\hline $\mathrm{Cr}^{3+}$ & 2.5 & 90.2 & 88.8 & $\mathrm{Cr}_{2} \mathrm{O}_{7}^{-}$ & 2.5 & 87.7 & 86.8 \\
\hline $\mathrm{Sn}^{2+}$ & 2.5 & 90.3 & 87.9 & $\mathrm{SO}_{3}^{2-}$ & 2.5 & 91.7 & 88.8 \\
\hline $\mathrm{Fe}^{3+}$ & 2.5 & 89.3 & 90.2 & $\mathrm{CH}_{3} \mathrm{COO}$ & 2.5 & 91.01 & 90.1 \\
\hline $\mathrm{Al}^{3+}$ & 2.5 & 89.1 & 92.2 & $\mathrm{~F}^{-}$ & 2.5 & 89.02 & 90.2 \\
\hline $\mathrm{Zn}^{2+}$ & 2.5 & 83 & 81.6 & $\mathrm{NO}_{2}^{-}$ & 2.5 & 90.01 & 92.0 \\
\hline $\mathrm{Pb}^{2+}$ & 2.5 & 85.7 & 81 & $\mathrm{CN}^{-}$ & 2.5 & 87.7 & 89.9 \\
\hline
\end{tabular}


Table 4: Desorption of Co (II) and Ni (II) by different eluents

\begin{tabular}{lcc}
\hline Eluents & \multicolumn{2}{c}{ \% Recovery } \\
& Co (II) & Ni (II) \\
\hline $1 \mathrm{M} \mathrm{HCl}$ & 72 & 73 \\
$2 \mathrm{M} \mathrm{HCl}$ & 69 & 71 \\
$3 \mathrm{M} \mathrm{HCl}$ & 75 & 76 \\
$1 \mathrm{M} \mathrm{HNO}_{3}$ & 85 & 82 \\
$2 \mathrm{M} \mathrm{HNO}_{3}$ & 87 & 86 \\
$3 \mathrm{M} \mathrm{HNO}_{3}$ & 90 & 91 \\
$3 \mathrm{M} \mathrm{CH}_{3} \mathrm{COOH}_{2}$ & 45 & 65 \\
$3 \mathrm{M} \mathrm{H}_{2} \mathrm{C}_{2} \mathrm{O}_{4}$ & 60 & 63 \\
\hline
\end{tabular}

the nature of the complexes are 1:1. The results are shown in Fig.8.

\section{Job's method of continuous variation}

For a fixed of the reagent concentration $(0.5 \mathrm{mg} / \mathrm{ml})$ with different concentration of the metal ions in the range of $5-100 \mathrm{ig} / \mathrm{ml}$ were studied. The natures of the curves predicting the nature of the complexes are 1:1. The results are shown in Fig.9.

\section{Effects of foreign ions}

As evident from [Table 3], in the solid phase spectrophotometric determination of $\mathrm{Co}$ (II) and $\mathrm{Ni}$ (II), the presence of macro amounts of foreign ions

Table 5: Determination of Co (II) and Ni (II) in real samples and tap water

\begin{tabular}{lccc}
\hline Samples & $\begin{array}{c}\text { Certified Value } \\
(\boldsymbol{\mu} \mathbf{g} / \mathbf{g})\end{array}$ & $\begin{array}{c}\text { Proposed method } \\
(\boldsymbol{\mu g} / \mathbf{g})\end{array}$ & \% RSD \\
\hline Tube Wells Water & Co (II) : 0.64 & 0.71 & 0.03 \\
& $\mathrm{Ni}(\mathrm{II}): 0.20$ & 0.35 & 1.0 \\
Tap water & $\mathrm{Co}(\mathrm{II}): 0.15$ & 0.20 & 0.06 \\
& $\mathrm{Ni}(\mathrm{II}): 0.25$ & 0.32 & 0.07 \\
Soil & $\mathrm{Co}(\mathrm{II}): 0.05$ & 0.07 & 0.08 \\
& $\mathrm{Ni}(\mathrm{II}): 0.05$ & 0.09 & 0.03 \\
\hline
\end{tabular}

The propposed structure of metal-ligand complexes

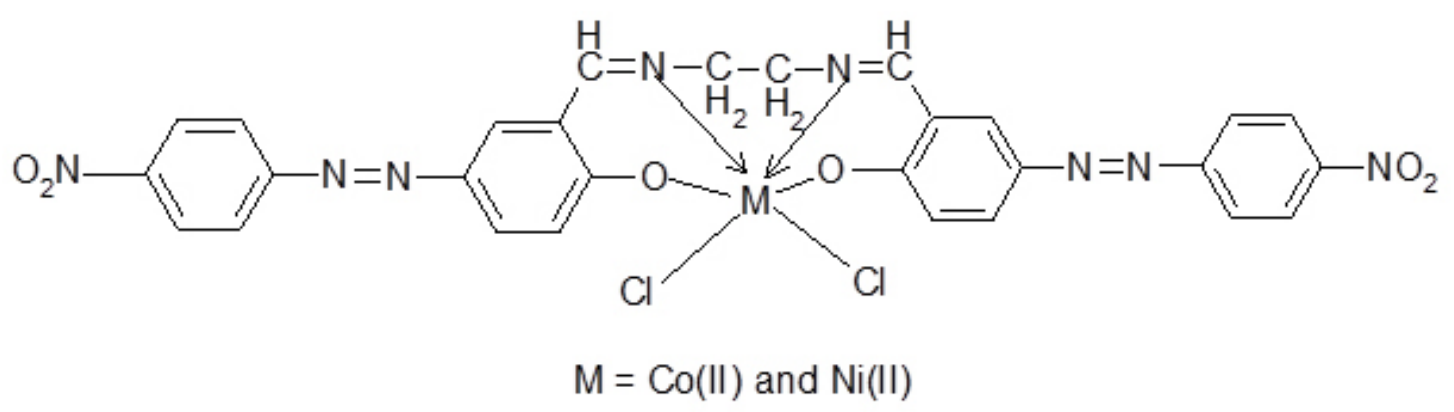

did not interfere in the sorption process. Only Zn (II) and $\mathrm{Pb}$ (II) interfere in very minute level. The results are presented in [Table 3].

\section{Effects of eluting agents on desorption of Co} (II) and Ni (II)

Various volumes of different eluents were applied for desorption of $\mathrm{Co}$ (II) and $\mathrm{Ni}$ (II) under optimum conditions. In this report 2-3M $\mathrm{HNO}_{3}$ was used as a general eluent that led to satisfactory results. Various volumes of $\mathrm{HNO}_{3}$ were used for extraction of each metal ions and it was found to increase by increasing its volumes. The results are shown in [Table 4].

\section{Analytical application}

The application of the proposed method at optimum condition was applied for determination 
of cobalt and nickel in various real samples and in environmental samples. The results are reported in [Table 5].

\section{CONCLUSION}

The proposed method is a selective, accurate and sensitive for the determination of Co (II) and Ni (II) ions based on complexation. The suggested method could be used for rapid determination of these two metal ions in real samples and tap water. The wide applicability and simplicity of the proposed method make it different from other existing methods.

\section{ACKNOWLEDGEMENT}

The authors are thankful to the Department of Chemistry of the University of Burdwan, Burdwan, India for providing the necessary laboratory facilities and the authors also thankful to Dr. Aniruddha Chakraborty from Union Christian Training College, Berhampore, Mushidabad, WB, India for his immense help in carrying out this research work.

\section{REFERENCES}

1. Moghimi Ali, Australian journal of Basic and Applied Sciences, 2012, 6(3), 349-355.

2. Rahman, Md. Faridur; Chakraborty, Aniruddha; and Das, Tanmoy, Orient. J.Chem., 2015, 31(4), pg. 2401-2408.

3. Rahman, M.F.; Chakraborty, A., and Das, T., IOSR Journal of Applied Chemistry (IOSRJAC), 2015, 1, pp.14-20

4. S Chauhan Jayprakash, V Pandya Ajit, International Journal of Eng. Sc. Invent, 2013, 2(2)

5. Rehman, F., and Mairaj, Samya, Orient. J.Chem., 2012, 28(2), pg. 881-885.

6. De, Anil K, Environmental Chemistry, Seventh Edition, New Age Int. Pub., 2010, pg 248.

7. Rahman, Md. Faridur; Chakraborty, Aniruddha; and Das, Tanmoy, Material Sc. Res. India, 2015, 12(2) pp.95-103.

8. Mukherjee, Dulal C; Chowdhury, Sumit B; Paul, Ajoy and Das, Paulomi, J. Indian Chem. Soc., 2012,89, pp.9-18.

9. Lokhande R.S., Sonawane P. Ratnamala and Chavan Utkarsha, Int. J. Chem. Sci., 2012,10(1), 342-348.

10. Moghimi Ali and Shahriare Ghammamy, Middle-East Journal of ScientificResearch, 2012, 12(10), 1331-1338.

11. Karayunlu, Seda; Ay, Umit, J. of Anal. Chem., 2010, 65, pp.244-248.

12. Rustamov, N.Kh; Abbasova, G.G., American J. Anal.Chem., 2014, 5, 275-280

13. Tavallali, H. and Kiani, S., Int. Journal of ChemTech Res., 2012, 4(3), pp.1182-1186.

14. Rahman, M. F.; Chakraborty, A., Bandyopadhyay, S. N.; Das, T., Golden
Research Thoughts, 2014, Vol.III, Issue.9, pp.1-6.

15. Hosaini Mehdi and Dalali Nasser, Indian Journal Chem. Tech., 2012, Vol.19, pp.337341.

16. Saritha B. and Reddy T. Sreenivasulu, IOSR Journal of Applied Chemistry(IOSR-JAC), 2014, 7(3), pp.22-26

17. Gopala Krishna D, Devanna N, Chandrasekhar K. B, Int. J Chem. Tech Res., 2011, 3(1), 506515

18. Pawar R B, Padgaonkar S B and Sawant A D, Indian J Chem. Tech., 2001, Vol.8, pp.200203.

19. Menon S K, Agrawal $\mathrm{Y} \mathrm{K}$ and Desai M N, Talanta, 1985, 36(6), 675.

20. Kumar R Kishore, Venkateswarlu S, Reddy Vijaya Kumar, Tulasamma P, Govinda V, Jyothi N V V and Venkateswarlu P, J. Chem. Pharm. Res., 2011, 3(3), pp.626-634.

21. Karayunlu Seda, Ay Umit, Journal of Anal. Chem., 2010, 65(3), pp.244-248.

22. Behpour Mohsen, Ghoreishi Sayed Mehdi and Salehi Sakineh, Acta Chim. Slov., 2005, 52, pp.323-327.

23. Saritha B. and Reddy T. Sreenivasulu, IOSR Journal of Applied Chemistry (IOSR-JAC), 2014, 7(3), pp.22-26.

24. Kumar A. Praveen, Reddy P Raveendra and Reddy V Krishna, Indian J. of Chem., 2007, Vol.46A, pp.1625-1629.

25. Rahman, Md. Faridur; Chakraborty, Aniruddha; and Das, Tanmoy, Am J. PharmTech. Res. 2015, 15(2), pp.496-506. 